\title{
EFFECTS OF TROPOSPHERIC AEROSOLS ON RADIATIVE FLUX CALCULATIONS AT UV AND VISIBLE WA VELENGTHS
}

\author{
Allen S. Grossman \\ Keith E. Grant \\ Global Climate Research Division \\ Lawrence Livermore National Laboratory \\ Livermore California 94550
}

August 1994

\begin{abstract}
The surface fluxes in the wavelength range 175 to $735 \mathrm{~nm}$ have been calculated for an atmosphere which contains a uniformly mixed aerosol layer of thickness $1 \mathrm{~km}$ at the earth's surface. Two different aerosol types were considered, a rural aerosol, and an urban aerosol. The visibility range for the aerosol layers was 95 to $15 \mathrm{~km}$. Surface flux ratios $(15 \mathrm{~km} / 95 \mathrm{~km})$ were in agreement with previously published results for the rural aerosol layer to within about $2 \%$. The surface flux ratios vary from 7 to $14 \%$ for the rural aerosol layer and from 13 to $23 \%$ for the urban aerosol layer over the wavelength range.

A tropospheric radiative forcing of about $1.3 \%$ of the total tropospheric fiux was determined for the $95 \mathrm{~km}$ to $15 \mathrm{~km}$ visibility change in the niral aerosol layer, indicating the potential of tropospheric feedback effects on the surface flux changes. This effect was found to be negligible for the urban aerosol layer. Stratospheric layer heating rate changes due to visibility changes in either the rural or urban aerosol layer were found to be negligible.
\end{abstract}




\section{INTRODUCTION}

In a recent publication (Grossman et al., 1993, GI)) the shor wavelength fluxes at atmospheric altitudes between 0 and $80 \mathrm{~km}$, in the wavelength range $175-735 \mathrm{~nm}$, were calculated and compared to publishel values, Validation studies were made for UV-A and UV-B ground radiation calculations (Madronich, 1993) as well as tropospheric radiative forcing calculations for various ozone distributions (Shine el al., 1994). The results showed good agreement with published results for the UV ground fluxes and the ozone tropospheric radiative forcing results performed under the IPCC 1994 test scenarios. The shor wavelength model has been described in detail by Grant and Grossman (1994). Although the model has the capability to include the effects of atmospheric aerosol distributions in the radiative flux calculations, none were included in the results of G1. Liu et al. (1991, L1) published results of the effect of anthropogenic acrosol distributions in the troposphere on shor wavelength surface fluxes. Using a $1 \mathrm{~km}$ boundary layer and a rural aerosol model, they found that the decrease of surface solar rodiation is approximately $12 \%$ at $310 \mathrm{~nm}$ and $10 \%$ at $550 \mathrm{~nm}$.

The main purpose of this paper is to extend the calculations of Gl to include the effects of a tropospheric aerosol layer and to perform a validation study with respect to the Ll calculations. In addition, the effects of urban as well as rural aerosol types were investigated.

\section{AEROSOL MODEL}

L1 adopted the relatiun given by Middleton (1963), which will also be adopted for the present calculations, relating the extinction coefficient, $\sigma\left(\mathrm{km}^{-1}\right)$, at $550 \mathrm{~nm}$ to the visual range, $R_{V}(k m)$.

$$
\sigma_{550}=3.912 / \mathrm{R}_{\mathrm{V}}
$$

The rural aerosol model adopted by $\mathrm{Ll}$ consisted of a bimodal aerosol size distribution composed of $70 \%$ watcr soluble and $30 \%$ dust like material at $70 \%$ relative humidity (Shettle and Fenn, 1979). For the calculations performed in this paper, the rural aerosol model optical properties given by Fenn et al. (1987) were used. Composite refractive indexes were determined at each wavelength. For the rural model the dry air composite refractive indexes were calculated using a $70 \%$ water soluble and a $30 \%$ dust like material mixture. The procedure outlined in Shettle and Fenn (1979) for the effective wet aerosol particle refractive index, namely the volume weighted average of the refractive indexes of the dry aerosol substance and water, was used in the present calculations. The optical properties of the rural aerosol components at wavelengths between 200 and $860 \mathrm{~nm}$ as well as the size distribution parameters at $70 \%$ relative humidity were used as input to a Mie scattering calculation to determine the extinction coefficient $(\sigma)$, single scattering albedo $(\omega)$, and the asymmetry factor (g) at each wavelength. The urban aerosol model given by Fenn et al. (1987) consisted of the rural aerosol mixture modified by the addition of a sont-like carbonaceous aerosol material. The proportions of the dry air soot-like aerosol and the rural aerosol materials were $20 \%$ and $80 \%$ respectively. Tables 1 and 2 show the values of $\sigma, \omega$, and $g$ for the rural and urban aerosol models at $70 \%$ relative humidity as a function of wavelength for distributions which provide the same extinction coefficient at $25 \mathrm{~km}$ visibility. According to $\mathrm{LI}$ the rural aerosol model calculations give an $\omega$ of 0.94 , approximately independent of wavelength, $g$ values of 0.66 at $550 \mathrm{~nm}$ and 0.69 at $310 \mathrm{~nm}$, and an altentiation coefficient, for $25 \mathrm{~km} R_{y}$, of $0.15 \mathrm{~km}^{-1}$ at $550 \mathrm{~nm}$ and $0.25 \mathrm{~km}^{-1}$ at $310 \mathrm{~nm}$. The results given in Table 1 for the present Mie calculations are in good agreement with the $\mathrm{Li}$ calculations. 


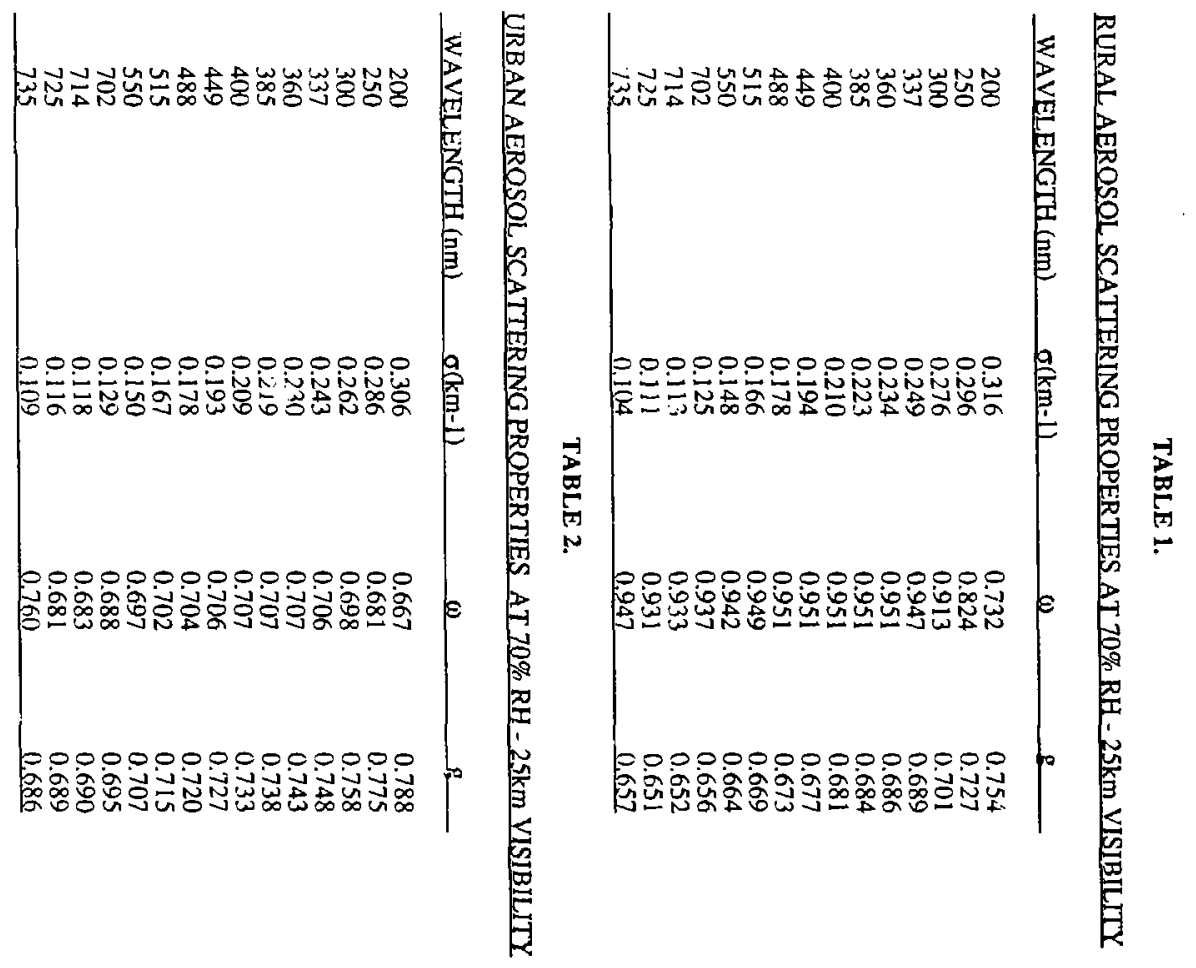


TABLE 3.

\section{LLNL, GLOBAL ANNUAL AVERAGE REFERENCE ATMOSPHERE}

\begin{tabular}{|c|c|c|c|c|c|c|c|c|}
\hline $\begin{array}{l}\text { Layer } \\
\text { Edge } \\
\text { Press } \\
(m b)\end{array}$ & $\begin{array}{l}\text { Layer } \\
\text { Mean } \\
\text { Press. } \\
(m b)\end{array}$ & $\begin{array}{c}\text { Layer } \\
\text { Mean } \\
\text { Temp. } \\
\{K\}\end{array}$ & $\begin{array}{c}\text { Luyer } \\
\text { Mean } \\
\text { Densiry } \\
\left.\left.\text { (molec } / \mathrm{cm}^{3}\right)^{3}\right)\end{array}$ & $\begin{array}{l}\text { Layer } \\
\text { Mean } \\
\mathrm{H}_{2} \mathrm{O} \\
\text { (ppv) }\end{array}$ & $\begin{array}{c}\text { Layer } \\
\text { Mean } \\
\mathrm{O}_{3} \\
\text { (ppmi) }\end{array}$ & $\begin{array}{c}\text { Layer } \\
\text { Mcan } \\
\mathrm{CO}_{2} \\
\text { (ppriv) }\end{array}$ & $\begin{array}{c}\text { Layer } \\
\text { Mean } \\
\mathrm{CH}_{4} \\
\text { (ppmv) }\end{array}$ & $\begin{array}{c}\text { Layer } \\
\text { Mean } \\
\mathrm{N}_{2} \mathrm{O} \\
\text { (ppin) }\end{array}$ \\
\hline
\end{tabular}

$2.4356 \mathrm{c}-01$ $3.2154 \mathrm{e}-01$ $4.2450 \mathrm{e}-01$ $5.6042 \mathrm{e}-01$ $7.3986 \mathrm{e}-01$ $9.7676 e .01$ $1.2895 e+00$ $1.7024 c+\infty 0$ $2.2475 e+00$ $2.967 l c+00$ $3.9172 c+00$

$5.1714 \mathrm{e}+00$ $6.8273 e+00$

$9.0133 c+00$

$1.1899 \mathrm{e}+01$

$1.5709 c+0 !$

$2.0739 e+01$

$2.7380 e+01$

$3.6147 e+01$

$4.7721 e+0 \mathrm{l}$

$6.3001 e+01$

$8.3173 \mathrm{e}+01$

$9.5566 e+01$

$1.0981 e+02$

$1.2617 \mathrm{e}+02$

$1.4496 e+02$

$1.6656 \mathrm{e}+02$

$1.9138 \mathrm{e}+02$

$2.1990 e+02$

$2.5266 e+02$

$2.9030 e+02$

$3.3356 e+02$

$3.8326 \mathrm{e}+02$

$4.4036 e+02$

$5.0597 e+02$

$5.8136 \mathrm{e}+02$

$6.6798 \mathrm{c}+02$

$7.6751=+02$

$8.8187 \mathrm{e}+02$

$1.0133 e+03$

\section{$2.8255 \mathrm{e}-01$} $3.7302 \mathrm{e}-0]$ $1.9246 \mathrm{e}-01$ $6.5014 c-01$ $8.5831 c-01$ $1.1331 e+00$ $1.4959 c+00$ $1.9749 e+\infty 0$ $2.6073 \mathrm{e}+00$ $3.4422 c+00$ $4.5443 \mathrm{e}+00$ $5.9994 c+00$ $7.9203 c+00$ $1.0456 \mathrm{c}+01$ $1.3904 c+01$ $1.8224 c+01$ $2.4059 c+01$ $3.1764 \mathrm{e}+01$ $4.193 d c+01$ $5.536 l e+01$

$7.3087 \mathrm{e}+01$ $8.9369 e+01$ $1.0269 \mathrm{e}+02$ $1.1799 c+02$ $1.3557 \mathrm{e}+02$ $1.5576 \mathrm{e}+02$ $1.7897 e+02$ $2.05640+02$ $2.3628 \mathrm{c}+02$ $2.7148 c+02$ $3.1193 e+02$ $3.5841 \mathrm{e}+02$ $4.1181 c+02$ $4.7316 c+02$ $5.4366 c+02$ $6.2467 a+02$ $7.1774 c+02$ $8.2469 c+02$ $9.475 \mathrm{x}+02$

\subsection{4}

253.12

258.47

262.73

265.08

266.15

264.76

261.71

257.33

251.99

246.67

240.92

235.44

230.68

226.16

223.03

220.52

218.05

215.49

212.86

210.08

208.47

207.19

208.58

210.18

212.01

215.51

219.53

224.15

229.15

234.89

241.49

247.78

255.01

261.64

268.10

273.74

279.58

286.06
$8.2373 e+15$

$1.0674 e+16$

$1.3800 \mathrm{e}+16$

$1.7923 a+16$

$2.3452 e+16$

$3.0837 e+16$

$4.0924 e+16$

$5.4657 e+16$

$7.3386 \mathrm{e}+1 \mathrm{c}$

$9.8937 \mathrm{e}+16$

L.3343e+17

$1.8036 \mathrm{e}+17$

$2.4365 \mathrm{e}+17$

$3.2830 \mathrm{e}+17$

$4.4208 \mathrm{c}+17$

$5.9182 \mathrm{k}+17$

$7.9023 c+17$

$1.0551 \mathrm{c}+18$

$1.4095 c+18$

$1.8837 e+18$

$2.5198 \mathrm{e}+18$

$3.1050 c+18$

$3.5897 e+18$

$4.0972 c+18$

$4.6716 \mathrm{e}+18$

$5.3212 e+18$

$6.0149 c+18$

$6.7846 e+18$

$7.6349 c+18$

$8.5809 e+18$

$9.6185 e+18$

$1.0750 \mathrm{e}+19$

$1.2038 \mathrm{e}+19$

$1.3439 \mathrm{e}+19$

$1.5050 \mathrm{e}+19$

$1.6876 \mathrm{e}+19$

$1.8991 \mathrm{c}+19$

$2.1365 c+19$

$2.3992 \mathrm{e}+19$
6.7112-06

$6.684 e-06$

6.655e-06

$6.638 \mathrm{e}-06$

6.58.ce-06

6.498e-06

$6.391 \mathrm{c}-06$

6.286e-06

(. $172 \mathrm{e}-06$

6.061e-06

$5.905 \mathrm{e}-06$

$5.702 \mathrm{e}-06$

$5.454 \mathrm{c}-06$

$5.199 \mathrm{e}-06$

$4.938 \mathrm{e}-06$

$4.753 \mathrm{e}-06$

$4.567 \mathrm{c}-06$

$4.380 \mathrm{e}-06$

$4.252 \mathrm{e}-06$

4.002e-06

$3.863 \mathrm{e}-06$

$4.281 \mathrm{e}-06$

$4.613 \mathrm{e}-06$

$9.726 \mathrm{e}-06$

1.560e-05

2.235e.05

4.976e.05

8.125e-05

$1.174 c-04$

2.668c-04

$1.385 \mathrm{e}-0.1$

$6.358 \mathrm{e}-04$

$1.161 \mathrm{e}-0$ ?

$1.765 \mathrm{e}-03$

$2.744 c-03$

$4.148 \mathrm{e}-03$

6.332: -03

$8.931 \mathrm{e}-03$

$1.195 \mathrm{e}-02$
$9.808 \mathrm{e}-0 \mathrm{I}$

$1.189 c+00$

$1.448 \mathrm{c}+00$

$1.735 c+\infty$

$2.073 c+00$

$2.481 \mathrm{c}+00$

$2.949 c+00$

$3.477 \mathrm{e}+00$

4.110c+00

$4.849 \mathrm{e}+00$

$5.625 c+00$

$6.477 e+00$

$7.276 \mathrm{e}+00$

$7.768 \mathrm{e}+00$

$7.931 \mathrm{e}+00$

$7.208 \mathrm{e}+00$

$6.060 c+00$

$4.655 \mathrm{e}+00$

$3.431 \mathrm{e}+00$

$2.4 t 3 c+\infty 0$

$1.460 c+00$

9.616e-01

$5.663 e-0$

$4.570 \mathrm{e}-0$

$3.315 \mathrm{e}-0$

$1.872 \mathrm{e} .0$

$1.627 \mathrm{e} .01$

$1.346 \mathrm{se}$

$1.022 \mathrm{e}-01$

9.072e-02

$7.750 \mathrm{e}-02$

$6.231 \mathrm{e}-02$

5.429e-02

$4.508 \mathrm{e}-02$

3.788e-02

3.174e-02

2.767e-02

$2.435 \mathrm{c} .02$

2.102e-02

$3.500 c+02$

$3.500 \mathrm{c}+02$

$1.548 \mathrm{c}-01$

$1.683 \mathrm{e}-01$

$1.215 e-03$

$1.771 \mathrm{e}-03$

$1.853 \mathrm{e}-01$

2.547e-03

$3.716 \mathrm{e}-03$

$5.547 \mathrm{e}-03$

$8.048 \mathrm{e}-03$

$1.126 \mathrm{c}-02$

L.506e-02

1.995e-02

2.661e-02

$3.764 \mathrm{e}-02$

$5.357 \mathrm{e}-02$

7.640c-02

1.022e-01

$1.311 \mathrm{e}-01$

$1.570 \mathrm{c}-01$

$3.500 \mathrm{e}+02$

$1071 e+00$

$1.148 \mathrm{e}+00$

$1.791 \mathrm{e}-01$

$3.500 c+02$

$1.227 \mathrm{e}+\infty 0$

$2.012 \mathrm{c}-01$

$2.225 \mathrm{e}-01$

$3.500 \mathrm{e}+02$

$1.308 \mathrm{e}+\infty 0$

$2.452 \mathrm{e}-01$

$3.500+02$

$1.494 \mathrm{e}+00$

$2.697 \mathrm{e}-01$

$3.500 e+02$

$1.558 \mathrm{c}+00$

$2.852 \mathrm{e}-01$

$3.500 \mathrm{e}+02$

$1.609 \mathrm{e}+00$

$2.974 \mathrm{e}-01$

$3.500 \mathrm{e}+02 \quad 1.614 \mathrm{e}+00$

$3.500 \mathrm{e}+02 \quad 1.619 \mathrm{e}+00$

$2.992 \mathrm{e}-01$ 


\section{RADIATIVE TRANSFER MODEL}

The input parameters to the radiative transfer model are;

1. Profiles of pressure, temperature,ozone, and water vapor,

2. Solar zenith angle,

4. Surface albedo at each wavelength.

5. Single scattering albedo and asymmetry factors at each wavelength.

The exo-atmospheric solar flux in each of 126 wavelength bins is taken from Connell and Wuebbles (1983) and is similar to WMO-16 (1985). Ozone cross sections have been taken from DeMore et al. (1992) and include temperature and pressure dependence. We consider ozone absorption, aerosols, and Rayleigh scattering as the major sources of lower atmospheric extinction in the short wavelength spectral range. Rayleigh scattering cross sections have been taken from Nicolet (1984). A two-stream flux model is used to calculate the diffuse irradiance incident on each atmospheric layer. The sources of upwards and downwards diffuse irradiance, due to scattering from the direct beam, are obtained by the use of a delta-Eddington approximation (King and Harshvardhan, 1986, Joseph et al., 1976). The single layer treatment for incident diftuse irradiance is treated by the Sagan-Pollack model for the diffuse reflection and transmission factors (Sagan and Pollack, 1976). The radiative transfer equations for a atmosphere model have been solved for the fluxes at each level using an adding method similar to that published by Gram and Hunt(1969) and Harshvardhan et. al (1987). At solar zenith angles greater than 75 degrees, the direct optical beam path is calculated using spherical geometry. For solar zenith angles between than 70 degrees and 75 degrees a weighted average of the plane parallel and spherical geometries is used. Clouds have not been included in this study although the radiative transfer model has the capacity for clouds to be included in the flux calculations

The model atmosphere used in the LI calculation is representative of $40^{\circ} \mathrm{N}$ for average summer conditions (July 21). The ozone profile was taken from Dutsch (1978). A wavelength independent surface albedo of $5 \%$ was assumed. For the calculations performed in this paper the global and annual average model atmosphere of Wuebbles et al. (1993) was used. The pressure-temperature-mixing ratio profiles for this atmosphere are given in Table 3 .

\section{TABLE 3}

An solar zenith angle of $48^{\circ}$ was used. This value approximates the average daylight solar zenith angle at $40^{\circ} \mathrm{N}$ on July 21 . As was the case for the $\mathrm{Ll}$ calculations, a flat surface albedo of $5 \%$ was assumed. The calculations were done for the clear sky approximation.

\section{RESULTS AND DISCUSSION}

\section{a. Rural Aerosol Layer Flux Validation Calculation}

Figure 1 shows the ratio of the surface flux calculated with an aerosol visibility of $15 \mathrm{~km}$ to that calculated with an aerosol visibility of $95 \mathrm{~km}$, for a $1 \mathrm{~km}$ thick uniformly mixed rural aerosol layer at the surface. The relative humidity is $70 \%$ and the wavelength range is 300 to $700 \mathrm{~nm}$. Curve LI-RU shows the Ll resulis and Curve ASGRU shows the 
results of the present calculations. Agreement between the two calculations is within about $2 \%$. The attenuation caused by the $15 \mathrm{~km}$ visibility aerosol layer varies from ahout $.14 \%$ at $300 \mathrm{~nm}$ to about $7 \%$ at $700 \mathrm{~nm}$ with respect to the $95 \mathrm{~km}$ visibility aerosol layer. Figure 2 shows the surface fluxes calculated for the clear sky, $15 \mathrm{~km}$ aerosol visibility, and $95 \mathrm{~km}$ aerosol visibility cases discussed above. The surface fuxes for an aerosol layer with $95 \mathrm{~km}$ visibility are about $3 \%$ less than those for the clear sky case.

\section{b. Urban Aerosol Layer Flux Calculation}

Figure 3 shows the ratio of the surface tlux calculated with an aerosol visibility of $15 \mathrm{~km}$ to that calculated with an aerosol visibility of $95 \mathrm{~km}$, for both a $1 \mathrm{~km}$ thick uniformly mixed rural and urban aerosol layer at the surface. The relative humidity is $70 \%$ and the wavelength range is 300 to $700 \mathrm{~nm}$. Curve URBAN shows the results for the urban aerosol layer and Curve RURAL shows the results for the nural aerosol layer. The attenuation caused by the $15 \mathrm{~km}$ visibility urban aerosol layer varies from about $23 \%$ at $300 \mathrm{~nm}$ to about $13 \%$ at $700 \mathrm{~nm}$ with respect to the $95 \mathrm{~km}$ visibility aerosol layer. The effect of the addition of the soot like material to the rural aerosol produces a significantly lower surface flux across the 300 to $700 \mathrm{~nm}$ wavelength region. Figure 4 shows the surface fluxes calculated for the $15 \mathrm{~km}$ aerosol visibility, and $95 \mathrm{~km}$ aerosol visibility rural and urban cases discussed above. The $95 \mathrm{~km}$ visibility urban aerosol layer fluxes are about $2 \%$ less than those for the rural aerosol layer while the $15 \mathrm{~km}$ visibility urban acrosol layer nuxes produce the major attenuation differences seen in Figure 3. The differences between the rural and urban aerosol layer flux results can be understood in terms of the consideration of the effects of the single scattering albedo $(\omega)$. The addition of the soot like material to the rural aerosol mixture to form the urban aerosol model results in a decrease of the single scattering albedo from $\sim 0.95$ to $\sim 0.71$ as shown in Tables 1 and 2 . A smaller va! of $\omega$ means that more of the downward radiation will be absorbed instead of being scattered resulting in a decrease in the transmission of radiation through the atmosphere and a lower surface flux (Joseph et al., 1976). Tables 1 and 2 indicate that the asymmetry factors for the urban aerosol are larger than those of the rural aerosol model. According to Joseph et al. (1976) this would tend to increase the transmission of the atmosphere but the effect is much smaller than that caused by the decrease in $\omega$.

\section{c. Aerosol Layer Effects on UV-A and UV-B Surface Radiation}

Figure 5 shows the ratio of the UV-B surface flux calculated with an aerosol visibility of $15 \mathrm{~km}$ to that calculated with an aerosol visibility of $95 \mathrm{~km}$, for both a $1 \mathrm{~km}$ thick uniformly mixed rural and urban aerosol layer at the surface. The relative humidity is $70 \%$ and the wavelength range is 280 to $320 \mathrm{~nm}$. Curve UVBRU shows the results of the rural aerosol layer and Curve UVBUR shows the results for the urban aerosol layer. On the average these curves would predict an attenuation ratio of about $23 \%$ for the urban aerosol layer and about $14 \%$ for the rural aerosol layer in going from a $95 \mathrm{~km}$ visibility to a $15 \mathrm{~km}$ visibility. Figure 6 shows the ratio of the UV-A surface flux calculated with an aerosol visibility of $15 \mathrm{~km}$ to that calculated with an aerosol visibility of $95 \mathrm{~km}$, for the rural and urban aerosol layers discussed above. The wavelength range is 320 to $400 \mathrm{~nm}$. Curve UVARU shows the results of the rural aerosol layer and Curve UVAUR shows the results for the urban aerosol layer. On the average these curves would predict an attenuation ratio of ahout $20 \%$ for the urban aerosol layer and about $12 \%$ for the rural aerosol layer in going from a $95 \mathrm{~km}$ visibility to a $15 \mathrm{~km}$ visibility. Figures 5 and 6 show that a tropospheric aerosol layer of $1 \mathrm{~km}$ thickness has the ability to attenuate harmful surface UV radiation by $12-23 \%$, depending on the aerosol visibility and type, and thus partially compensate for the loss of stratospheric ozone on a local level. 


\section{d. Heating Rate And Radiative Forcing Erfects Of The Aerosol Layer}

The addition of the $1 \mathrm{~km}$ rural acrosol layer will causc a tropospheric radiative forcing of about $-10.1 \mathrm{~W} / \mathrm{m}^{2}$, over the wavelength range 175 to $735 \mathrm{~nm}$, when the visibility goes from $95 \mathrm{~km}$ to $15 \mathrm{~km}$. This forcing is about $1.3 \%$ of the total tropospheric flux. The consequences of this forcing would be that the tropospheric temperatures would adjust to the forcing, thus changing the tropospheric chemistry and absorption coefficients, which might result in a feedback that would decrease the flux difference caused by the aerosol visibility change. There is negligible tropospheric radiative forcing for the same visibility change in the urban aerosol layer. This is probably due to the more absorptive and less reflective nature of the rural aerosol layer evidenced by the lower values of $\omega$. These results are in agreement with the results of Joseph et al. (1976). Heating rates were calculated for a typical stratospheric layer to determine if there were heating rate changes caused by visibility changes in the surface aerosol layer. For the cases considered in this paper no heating rate changes were observed when the visibility changed from $95 \mathrm{~km}$ to $15 \mathrm{~km}$ in either the rural or urban aerosol layer. Fu:ure studies will address the subject of radiative forcing and heating rate changes for a wider choice of acrosol types, visibility changes, layer thicknesses, and atmospheric models in more detail.

\section{ACKNOWLEDGMENT}

Work was performed under the auspices of the U. S. Department of Energy by the Lawrence Livermore National Laboratory under contract W-7405-Eng-48 and was supported in part by the Depariment of Energy Office of Environmental Analysis.

\section{REFERENCES}

Connell, P., and D.W. Wuebbles, 1983: Summary of photochemical and radiative data used in the LLNL one-dimensional transport-kinetics model of the troposphere and stratosphere: 1982. LLNL Report UCID-19657-82, Jan. 1983.

DeMore, W.B., S.P. Sander, D.M. Golden, R.F. Hampson, M.J. Kurylo, C.J. Howard, A.R. Ravishankara, C.E. Kolb, and M.J. Molina, 1992: Chemical kinetics and photochemical data for use in stratospheric modeling: Evaluation 10, NASA JPL Report JPL Publication 92-20, August 1992.

Dutsch, H. U., 1978: Vertical ozone distribution on a global scale, Pure Appl. Geophys., 116. pp. $511-529$.

Fenn, R. W., S. A. Clough, W. O. Gallery, R. E. Good, F. X. Kneizys, J. D. Mill, L. S. Rothman, E. P. Shettle, and F. E. Volz, 1987: Optical and infrared properties of the atmosphere, Chapter 18 in Handbook of Geophisics and the Space Environment, ed. A. S. Jursa, Air Force Geophysics Laboratory, Hanscom AFB, Mass.

Grant K.E., and A.S. Grossman, LLNL Report UCRL (in press).

Grant I.P., and G.E. Hunt, 1969: Discrete space theory of radiative transfer. 1. Fundamentals, Proc. R. Soc. London, Ser. A, 313, pp. 183-197.

Grossman, A.S., Grant, K.E., and D.J. Wuebbles, 1993: Radiative flux calculations at UV and visible wavelengths, LLNL Repor UCRL-ID-115336. (GI). 
Harshvardhan, R: Davies, D.A. Randall, and T.G. Corsetti, 1987: A fast radiation parameterization for atmospheric circulation models, J. Geophys. Res. , Vol. 92, Dl, pp. 1009-1016.

Joseph, J. H., W. J. Wiscombe, and J. A. Weinman, 1976: The delta eddington approximation for radiative flux transfer. J. Atmos. Sci. , 33, 2452 - 2459

King, M.D., and Harshvardhan, 1986, Comparative accuracy of selected multiple scattering approximations, J. Atmos. Sci. . 43, pp. 784-801.

Liu, S. C., S. A. McKeen, and S. Madronich, 1991: Effect of anthropogenic aerosols on biologically active ultraviolet radiation, Geophys. Res. Letts., 18, pp. 2265 - 2268 (L1).

Madronich, S.. 1993, Chapter 2: UV radiation in the natural and perturbed atmosphere, Effects of UV-B Radiation On Humans, Animals, Plants, Microorganisms and Materials, edited by M. Trevini, Lewis Publishers/CRC Press, (in press).

Nicolet, M., 1984: On the molecular scattering in the terrestrial atmosphere: An empirical for its calculation in the homosphere, Planet, and Space Sci., 32, 1467-1468.

Sagan, C., and J.B. Pollack, 1967: An isotropic nonconservative scattering and the clouds of Venus, J. Geophys. Res., 72, pp. 469-477.

Shetcle, E. P., and R. W. Fenn, 1979: Models for acrosols of the lower atmosphere and the effects of humidity variations on their optical properties, Report AFGL-TR-790214, Air Force Geophysics Laboratory, Hanscom AFB, Mass.

Shine, K. P., A. S. Grossman, D. Hauglustaine, V. Ramaswamy, M. D. Schwarzkopf, R. van Dorland, W. C. Wang and others, 1994: An intercomparison of radiative forcing due to ozone changes by different modeis. to be presented at the NATO ARW - Atmospheric Ozone As A Climat a Gas, Oslo Norway June 20 - 24.

WMO-16, 1985: Atmospheric ozone 1985: Assessment of our understanding of the processes controlling its present distribution and change, Vol. 1, Report No. 16 , World Meteorological Organization, pp. 349-378.

Wuebbles, D.J., A.S. Grossman, J.S. Tamaresis, K.O. Paten, A. Jain, and K.E. Grant, 1993: Indirect global warming effects of tropospheric ozone induced by surface methane emission. LLNL Report UCRL (in press). 


\section{FIGURE CAPTIONS}

Figure 1. The ratio of the surface flux calculated with an aerosol visibility of $15 \mathrm{~km}$ to that calculated with in aerosol visibility of $95 \mathrm{~km}$, for a $1 \mathrm{~km}$ thick uniformly mixed rural aerosol layer at the surface. The relative humidity is $70 \%$ and the wavelength range is 300 to $700 \mathrm{~nm}$. Curve MADRU shows the $\mathrm{Ll}$ results and Curve ASGSOLRU shows the results of the present calculations.

Figure 2. The surface fluxes calculated for the clear sky, $15 \mathrm{~km}$ aerosol visibility, and $95 \mathrm{~km}$ aerosol visibility cases or a $1 \mathrm{~km}$ thick uniformly mixed rural aerosol layer at the surface. The relative humidity is $70 \%$ and the wavelength range is 300 to $700 \mathrm{~nm}$. Curve FLUXCLR illustrates the clear sky results, Curve FLUX95RU illustrates the $95 \mathrm{~km}$ visibility case, and Curve FLUX15RU illustrates the $15 \mathrm{~km}$ visibility case.

Figure 3. The ratio of the surface flux calculated with an aerssol visibility of $15 \mathrm{~km}$ to that calculated with an aerosol visibility of $95 \mathrm{~km}$, for both a $1 \mathrm{~km}$ thick uniformly mixed rural and urban aerosol layer at the surface. The relative humidity is $70 \%$ and the wavelength range is 300 to $700 \mathrm{~nm}$. Curve ASGSOLUR shows the results for the urban aerosol layer and Curve ASGSOLRU shows the results for the rural aerosol layer.

Figure 4. The surface fluxes calculated for the $15 \mathrm{~km}$ aerosol visibility, and $95 \mathrm{~km}$ aerosol visibility cases or a $1 \mathrm{~km}$ thick uniformly mixed rural aerosol layer and a $1 \mathrm{~km}$ thick uniformly mixed urban aerosol layer at the surface. The relative humidity is $70 \%$ and the wavelength range is 300 to $700 \mathrm{~nm}$. Curve FLUX95RU illustrates the $95 \mathrm{~km}$ visibility rural case, Curve FLUX15RU illustrates the $15 \mathrm{~km}$ visibility rural case, Curve FLUX95UR illustrates the $95 \mathrm{~km}$ visibility urban case, and Curve FLUX15UR illustrates the $15 \mathrm{~km}$ visibility urban case.

Figure 5. The ratio of the UV-B surface flux calculated with an aerosol visibility of $15 \mathrm{~km}$ to that calculated with an aerosol visibility of $95 \mathrm{~km}$, for both a $1 \mathrm{~km}$ thick uniformiy mixed rural and urban aerosol layer ar the surface. The relative humidity is $70 \%$ and the wavelength range is 280 to $320 \mathrm{~nm}$. Curve UVBRATRU shows the results for the rural aerosol layer and Curve UVBRATUR shows the results for the urban aerosol layer.

Figure 6. The ratio of the UV-A surface flux calculated with an aerosol visibility of $15 \mathrm{~km}$ to that calculated with an aerosol visibility of $95 \mathrm{~km}$, for both a $1 \mathrm{~km}$ thick uniformly mixed rural and urban aerosol layer at the surface. The relative humidily is $70 \%$ and the wavelength range is 280 to $320 \mathrm{~nm}$. Curve UVARATRU shows the results for the rural aerosol layer and Curve UVARATUR shows the results for the urban aerosol layer. 
RATIO OF $15 \mathrm{~km}$ FLUX TO $95 \mathrm{~km}$ FLIJX

VS WAVELENGTH FOR RURAL AEROSOL LAYER

$1 \mathrm{~km}$ THICK AT $70 \%$ RH

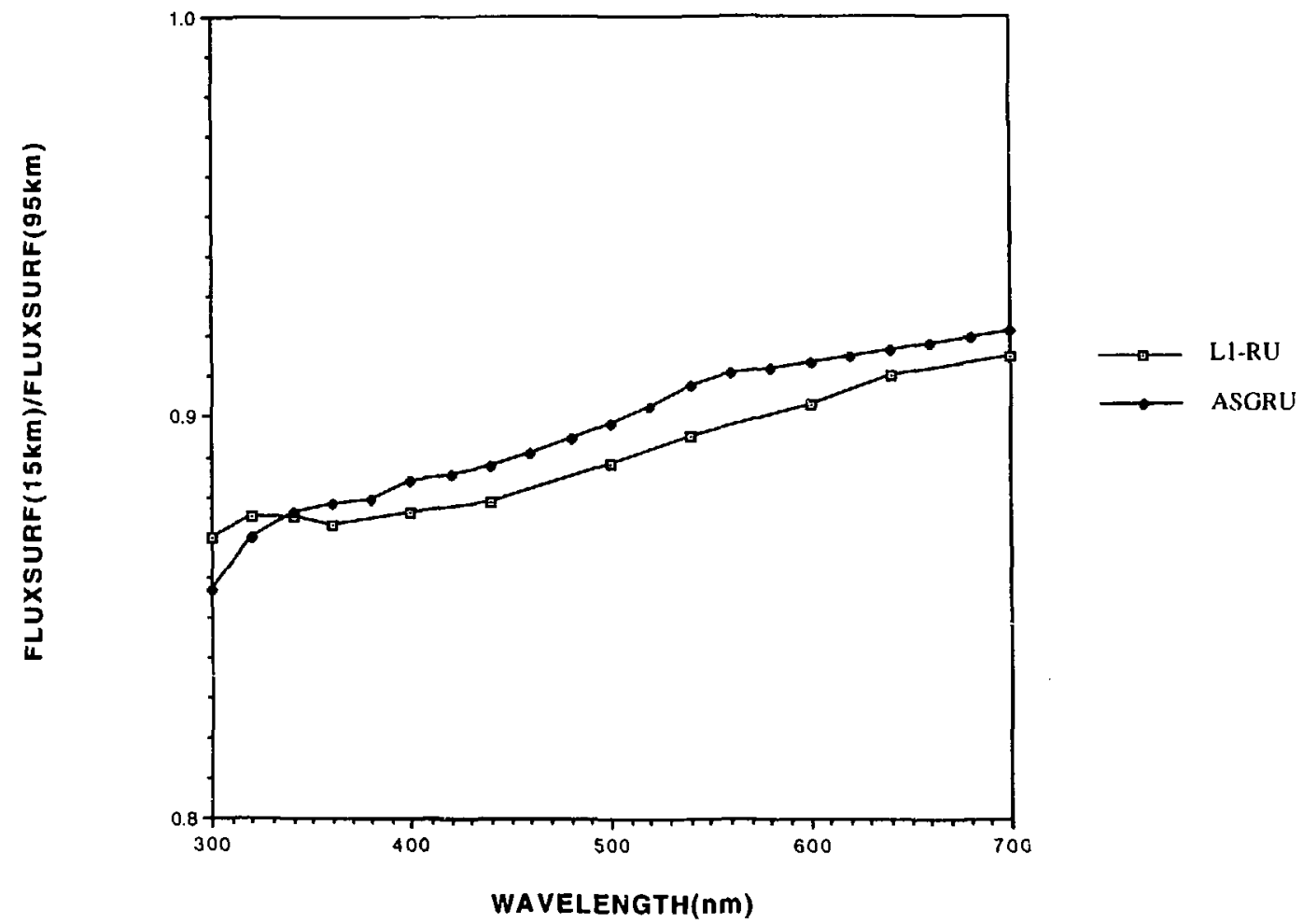



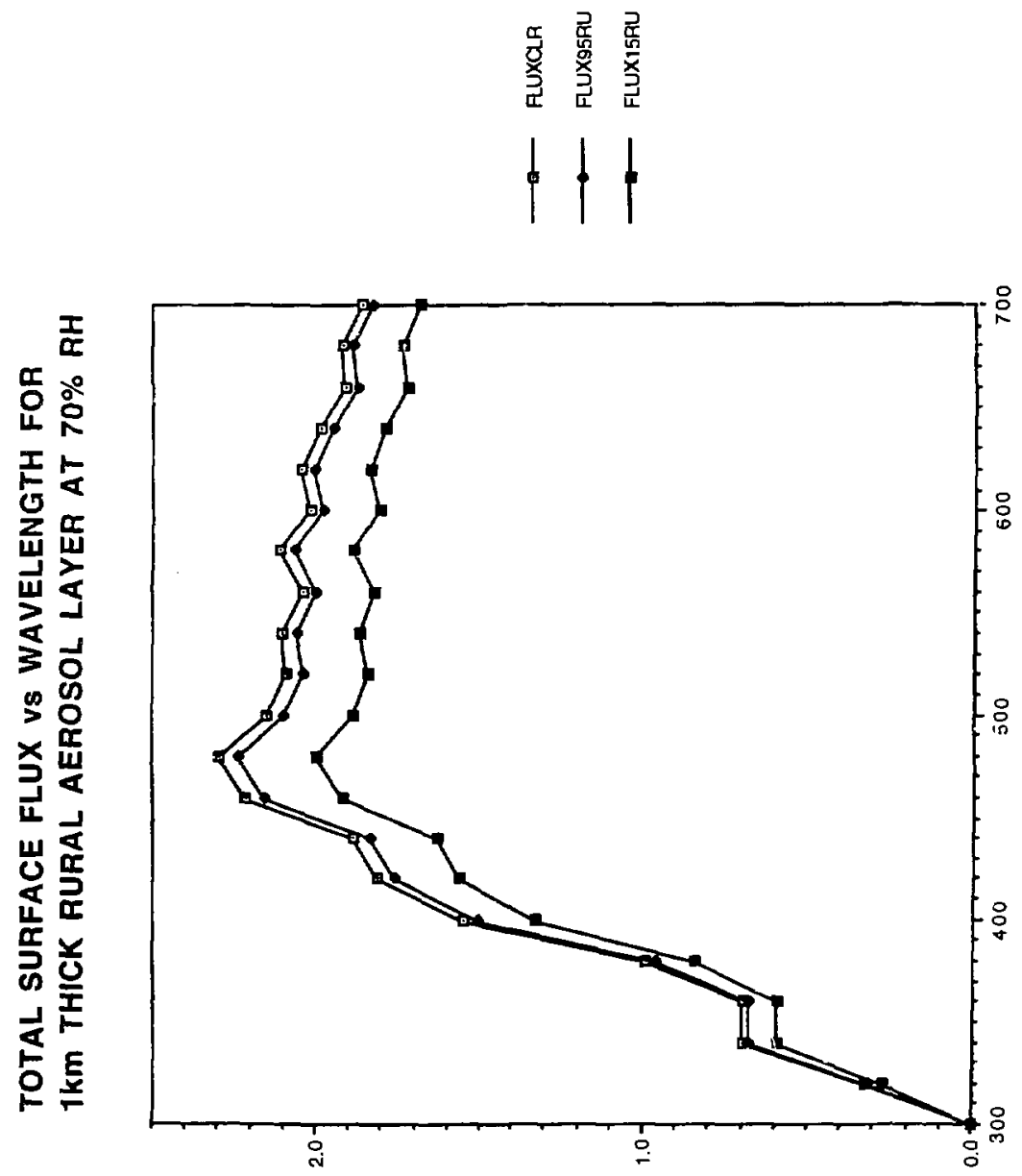

E

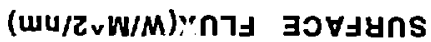


COMPARISON OF FLUX RATIO

$(15 \mathrm{~km}$ is $/ 95 \mathrm{~km}$ vis) vs WAVELENGTH FOR

$1 \mathrm{~km}$ THICK RURAL AND URBAN AEROSOL LAYER
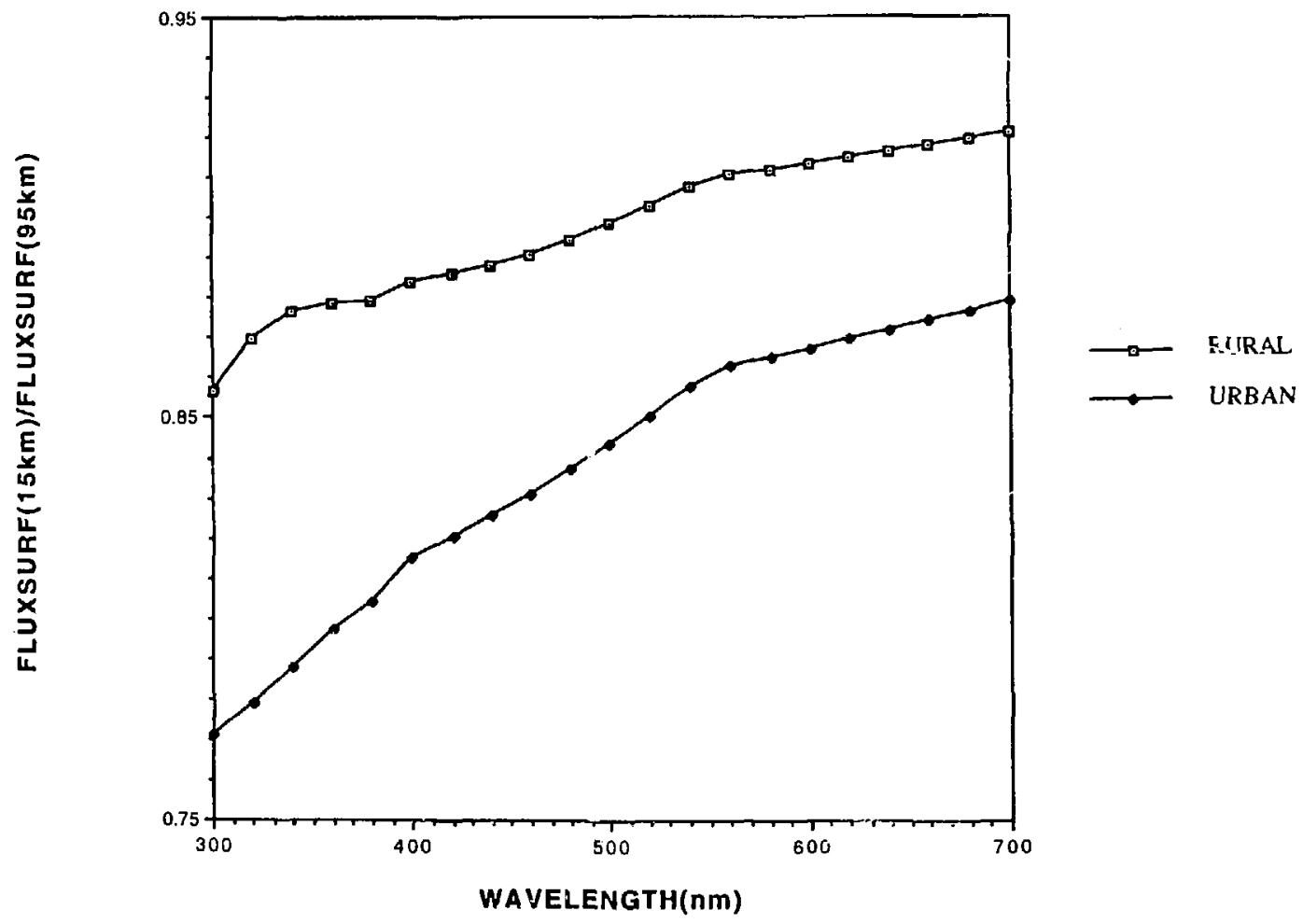
TOTAL SURFACE FLUX VS WAVELENGTH

FOR $1 \mathrm{~km}$ RURAL AND URBAN AEROSOL LAYERS

AT $70 \%$ RH

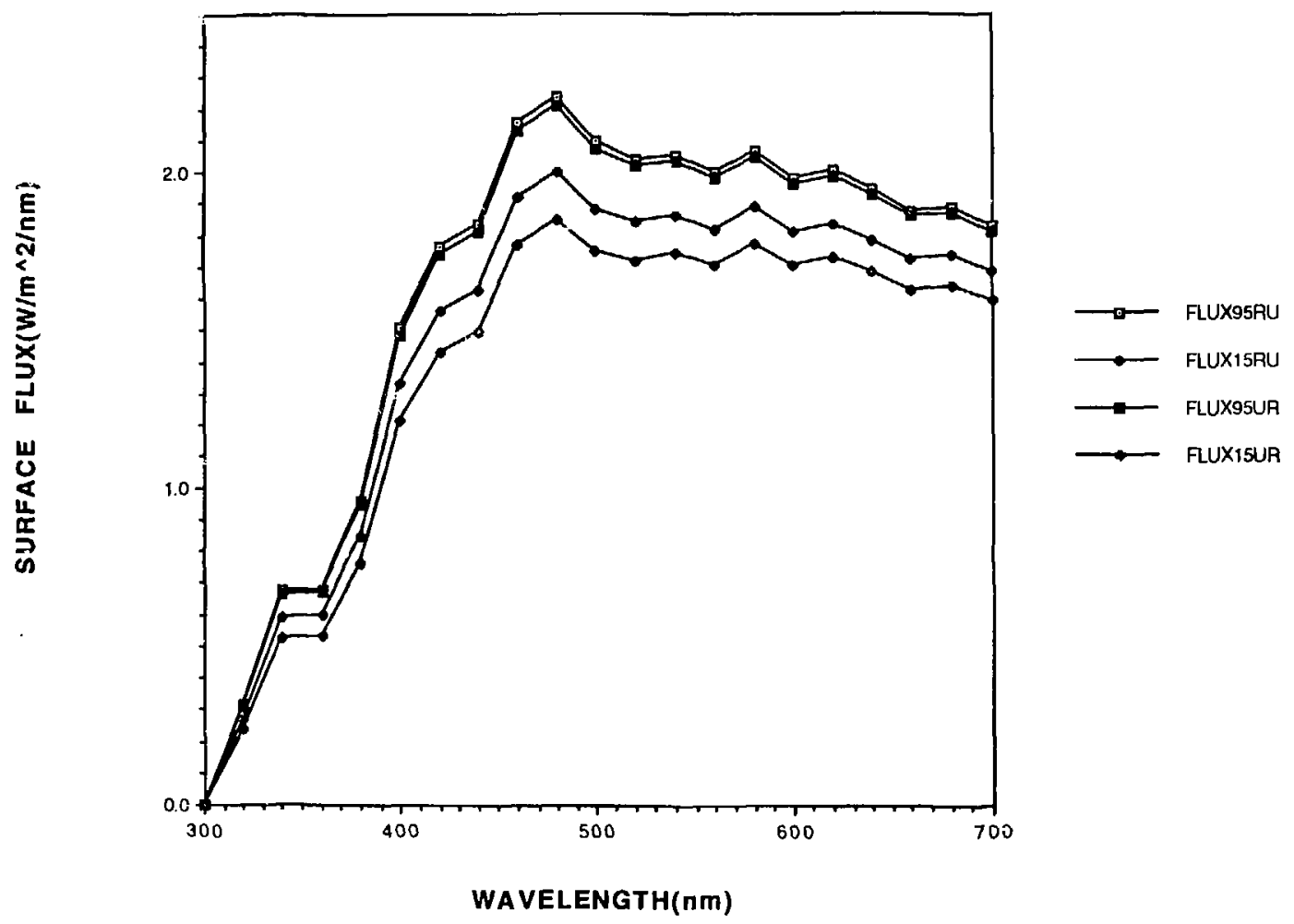


COMPARISON OF UV-S SURFACE FLUX RATIO

$(15 \mathrm{~km}$ vis $195 \mathrm{~km}$ vis) VS WVAVELENGTH FOR

RURAL AND URBAN AEROSOL LAYERS AT $70 \%$ RH

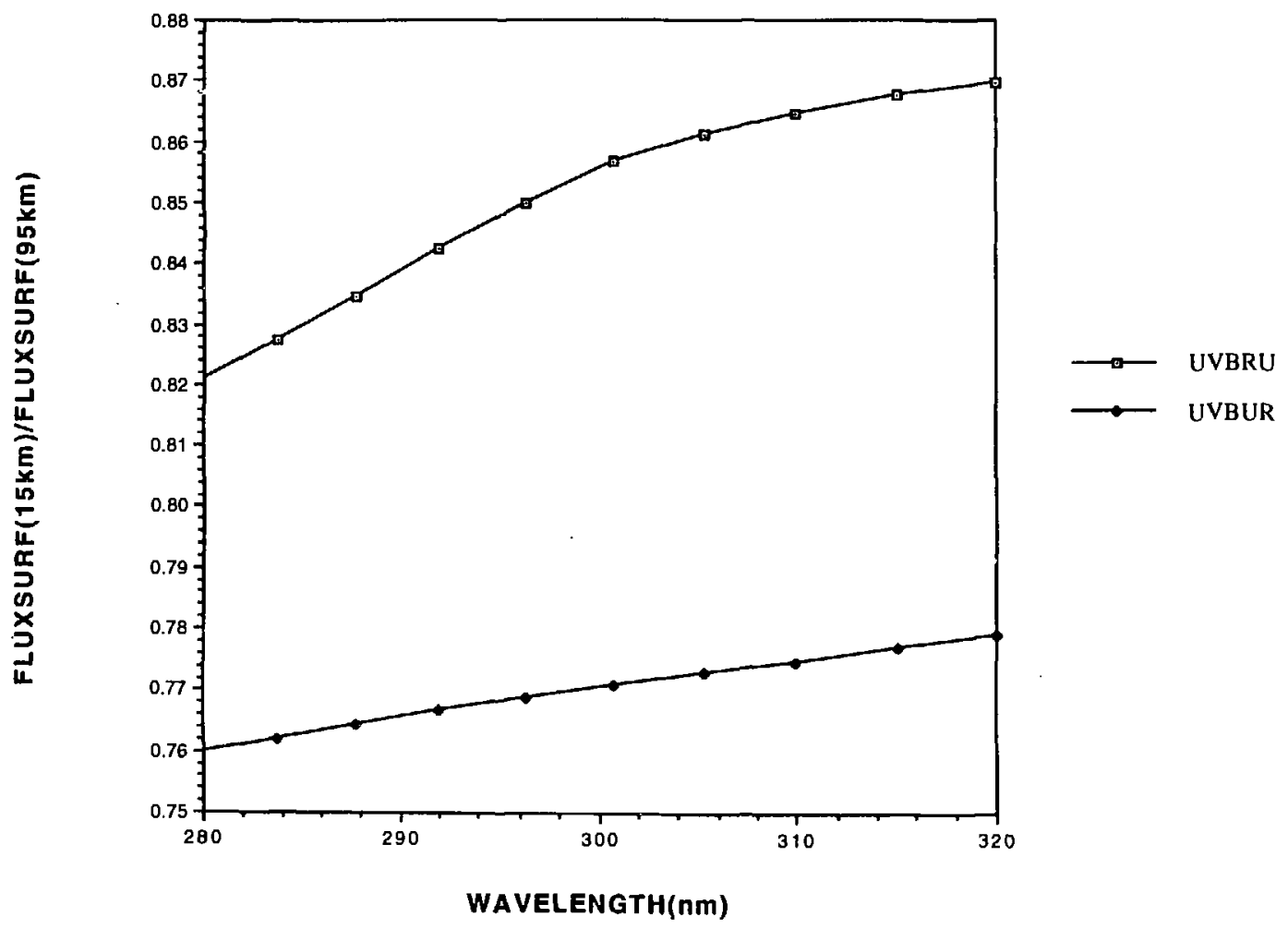


COMPARISON OF UV-A SUAFACE FLUX RATIO (15km vis $/ 95 \mathrm{~km}$ vis) vS WAVELENGTH FOR

RURAL AND URBAN AEROSOL LAYERS AT 70\% RH

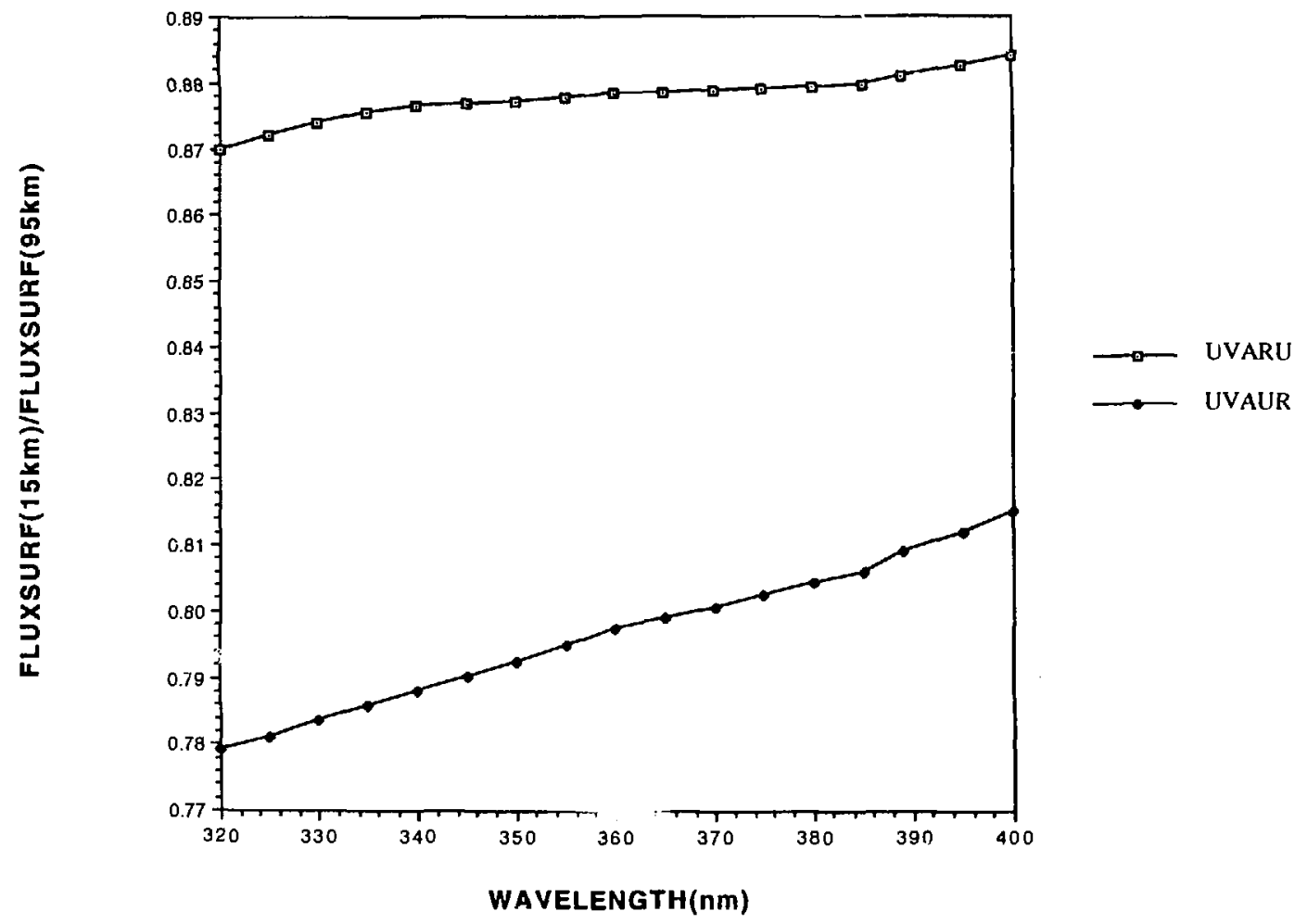

